\title{
Sex Disparities in COVID-19 Mortality Vary Across US Racial Groups
}

\author{
Tamara Rushovich, M.P.H. ${ }^{1,2}$ (D), Marion Boulicault, MPhil ${ }^{3,4}$, Jarvis T. Chen, Sc. D. ${ }^{2}$, \\ Ann Caroline Danielsen, MSc., M.P.H. ${ }^{2}$, Amelia Tarrant5, Sarah S. Richardson, Ph.D., 5, \\ and Heather Shattuck-Heidorn, Ph.D. ${ }^{7}$
}

\begin{abstract}
'Population Health Sciences Department, Harvard Graduate School of Arts and Sciences, Cambridge, MA, USA; ${ }^{2}$ Department of Social and Behavioral Sciences, Harvard T.H. Chan School of Public Health, Boston, MA, USA; ${ }^{3}$ Department of Linguistics and Philosophy, Massachusetts Institute of Technology, Cambridge, MA, USA; ' ${ }^{2}$ epartment of Philosophy, University of Adelaide, Adelaide, Australia; ${ }^{5}$ Studies of Women, Gender, and Sexuality, Harvard University, Cambridge, MA, USA; ${ }^{6}$ Department of the History of Science, Harvard University, Cambridge, MA, USA; ${ }^{7}$ Women and Gender Studies, University of Southern Maine, Portland, Maine, USA.
\end{abstract}

BACKGROUND: Inequities in COVID-19 outcomes in the USA have been clearly documented for sex and race: men are dying at higher rates than women, and Black individuals are dying at higher rates than white individuals. Unexplored, however, is how sex and race interact in COVID-19 outcomes.

OBJECTIVE: Use available data to characterize COVID19 mortality rates within and between race and sex strata in two US states, with the aim of understanding how apparent sex disparities in COVID-19 deaths vary across race.

DESIGN AND PARTICIPANTS: This observational study uses COVID-19 mortality data through September 21, 2020, from Georgia (GA) and Michigan (MI).

MAIN MEASURES: We calculate age-specific rates for each sex-race-age stratum, and age-standardized rates for each race-sex stratum. We investigate the sex disparity within race groups and the race disparity within sex groups using age-standardized rate ratios, and rate differences.

KEY RESULTS: Within race groups, men have a higher COVID-19 mortality rate than women. Black men have the highest rate of all race-sex groups (in MI: 254.6, deaths per 100,000, 95\% CI: 241.1-268.2, in GA:128.5, 95\% CI: 121.0-135.9). In MI, the COVID-19 mortality rate for Black women (147.1, 95\% CI: 138.7-155.4) is higher than the rate for white men (39.1, 95\% CI: 37.3-40.9), white women (29.7, 95\% CI: 28.3-31.0), and Asian/ Pacific Islander men and women. COVID-19 mortality rates in GA followed the same pattern. In MI, the male:female mortality rate ratio among Black individuals is 1.7 (1.5-2.0) while the rate ratio among White individuals is only $1.3(1.2-1.5)$.

CONCLUSION: While overall, men have higher COVID-19 mortality rates than women, our findings show that this sex disparity does not hold across racial groups. This demonstrates the limitations of unidimensional reporting and analyses and highlights the ways that race and gender intersect to shape COVID-19 outcomes.

Prior Presentations No prior presentations given

Received October 1, 2020

Accepted March 4, 2021

Published online April 5, 2021
KEY WORDS: COVID-19; health inequities; intersectionality; sex/gender; race/ethnicity.

J Gen Intern Med 36(6):1696-701

DOI: $10.1007 / \mathrm{s} 11606-021-06699-4$

(C) Society of General Internal Medicine 2021

\section{INTRODUCTION}

An apparent sex difference in COVID-19 outcomes has emerged; in many places men are more likely to die than women, though this magnitude varies substantially across locales. ${ }^{1}$ Racial disparities in COVID-19 outcomes have also emerged in the USA. ${ }^{2,}{ }^{3}$ Yet, the relationships between sex, race, and COVID-19 outcomes in the USA have been unexplored. Lack of analysis of these relationships is a critical research gap for reasons both applied and theoretical. Ecosocial theory ${ }^{4}$, as well as Black feminist theory and the related framework of intersectionality, ${ }^{5}$ has long established that intersecting systems of power and oppression structure risk in diverse ways across and within categorical groups. ${ }^{6}$ Unidimensional analysis creates a universal "man" who is more at risk of death from COVID-19 than the corresponding "woman." In reality, health risks are structured in complex ways that reflect systemic and broader societal inequities. In this study, we use data from Georgia (GA) and Michigan (MI) - the only two states reporting age-, race- and sex-disaggregated COVID-19 mortality data - to analyze interactions between race and sex, with the aim of understanding how apparent sexdisparities in COVID-19 deaths vary across race.

\section{MATERIALS AND METHODS}

We used publicly available datasets of COVID-19 deaths (accessed on September 21, 2020) from the Georgia Department of Public Health ${ }^{7}$ and the Michigan Department of Health and Human Services. ${ }^{8}$ State-level data were used because COVID-19 mortality data are not available disaggregated by age, race, and sex at the federal level in the USA. The 
2018 bridged-race population estimates (2018 vintage) were obtained from the Centers for Disease Control and Prevention and used as population denominators in all rate calculations. ${ }^{9}$ Rates are reported per 100,000 people.

To account for differences in age distributions across race and sex groups, we calculated both age-specific and agestandardized COVID-19 mortality rates. Age-specific mortality rates by race and sex were calculated by dividing the number of deaths in each age-race-sex stratum by the total population of that stratum residing in each state. ${ }^{10}$ Confidence intervals were calculated using standard methods. ${ }^{11}$ Directly age-standardized rates produced using cited methods, including using the 2000 US population as the standard, are particularly useful as they can be compared to reported national and state age-standardized rates. ${ }^{12}$

To understand how the sex disparity differs across race groups, the age-standardized mortality rate ratio and rate differences were calculated non-parametrically and compared for MI and for GA. These age-standardized mortality rate ratios and rate differences were calculated between sex categories within race groups and between race groups within sex categories. Additionally, age-standardized mortality rate ratios were calculated using a common reference group for different sex-race comparisons ${ }^{13}$. Standard errors and confidence intervals for rate ratios and rate differences were calculated using standard methods for mortality data. ${ }^{14}$

Categorization of the race, sex, and age variables was limited by how the data were reported. The following age categories were used: 0-39 years, $40-49$ years, 50-59 years, 60-69 years, 70-79 years, and 80 years and older. Ethnicity (e.g., Latinx or Hispanic) was not provided in the data for either state. The Michigan dataset suppressed cells when the number of deaths in a single age-sex-race category was between one and five. Race was categorized as Black, white, or Asian/Pacific Islander (Asian/PI). American Indian and Alaskan Native were not included in the analysis due to small numbers. Sex was categorized as male or female. Race, age, or sex categorized as "other" or "unknown" were excluded from the analysis. These data and analyses are exempt from Institutional Review Board approval review as only publicly available de-identified data were used.

\section{RESULTS}

Men had consistently higher COVID-19 mortality rates than women within age and race strata (Tables 1 and 2). For example, in GA, among individuals aged 70-79 the rate among white men and white women respectively was 235.5 per 100,000 (95\% CI: 215.8-256.5) and 156.6 (141.8-172.6); among Black men and Black women was 675.7 (611.8-744.4) and 364.0 (325.1-406.2); and among Asian/PI men and Asian/PI women was 294.8 (192.6-431.9) and 115.1 (59.4 201.0) (Table 1).
Table 1 COVID-19 Mortality by Race, Age, and Sex in Georgia, USA

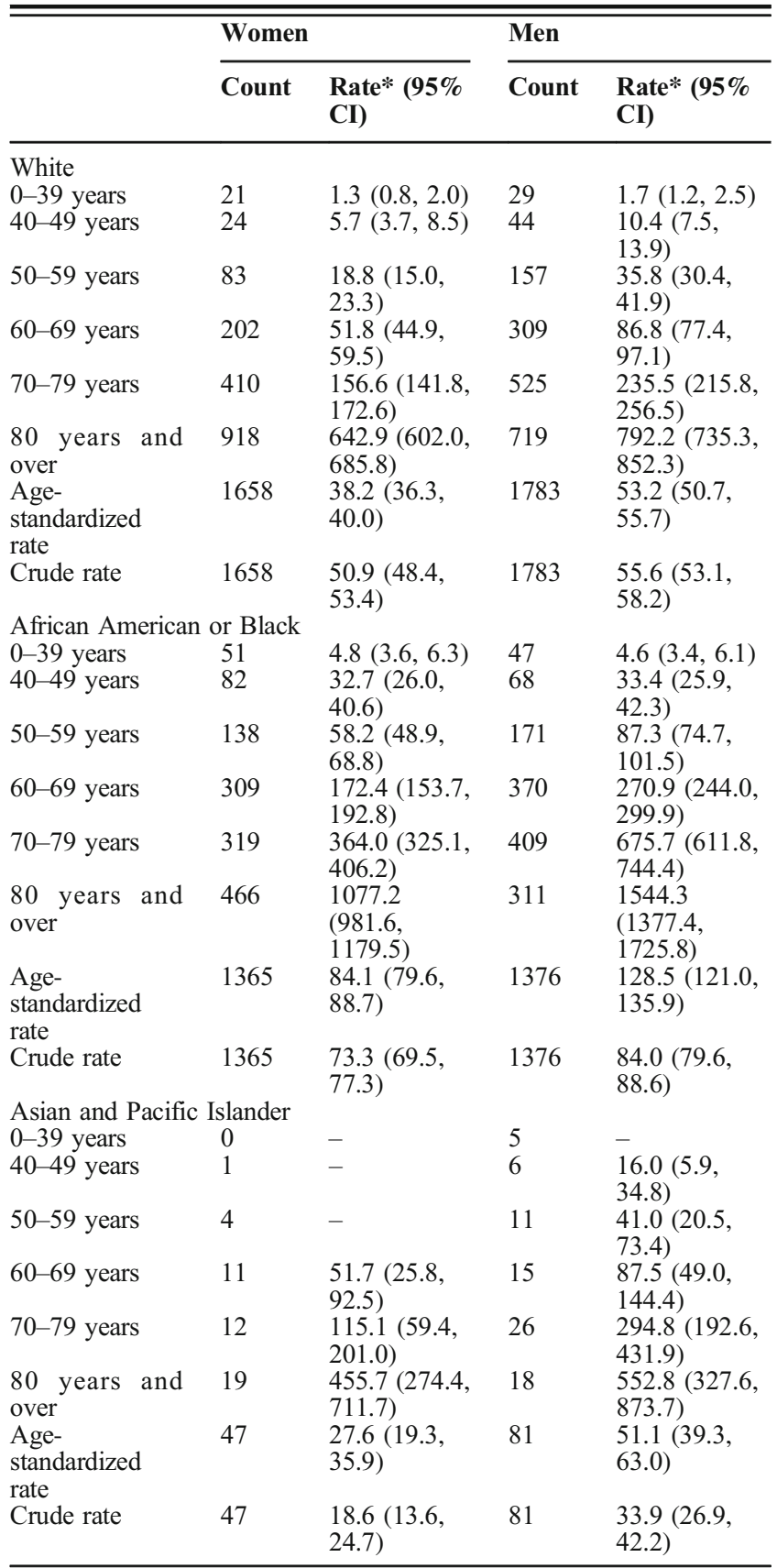

* Rate per 100,000

-Rates for counts less than or equal to five may be statistically unstable and are not reported

The direct age-standardized mortality rates for race and sex groups in GA were 53.2 (95\% CI: 50.7-55.7) for white men, $38.2(36.3-40.0)$ for white women, 128.5 (121.0-135.9) for Black men, 84.1 (79.6-88.7) for Black women, 51.1 (39.363.0) for Asian/PI men, and 27.6 (19.3-35.9) for Asian/PI women (Table 1). The MI data showed a similar pattern: 39.1 (37.3-40.9) for white men, 29.7 (28.3-31.0) for white women, 254.6 (241.1-268.2) for Black men, 147.1 (138.7-155.4) for 
Table 2 COVID-19 Mortality by Race, Age, and Sex in Michigan, USA

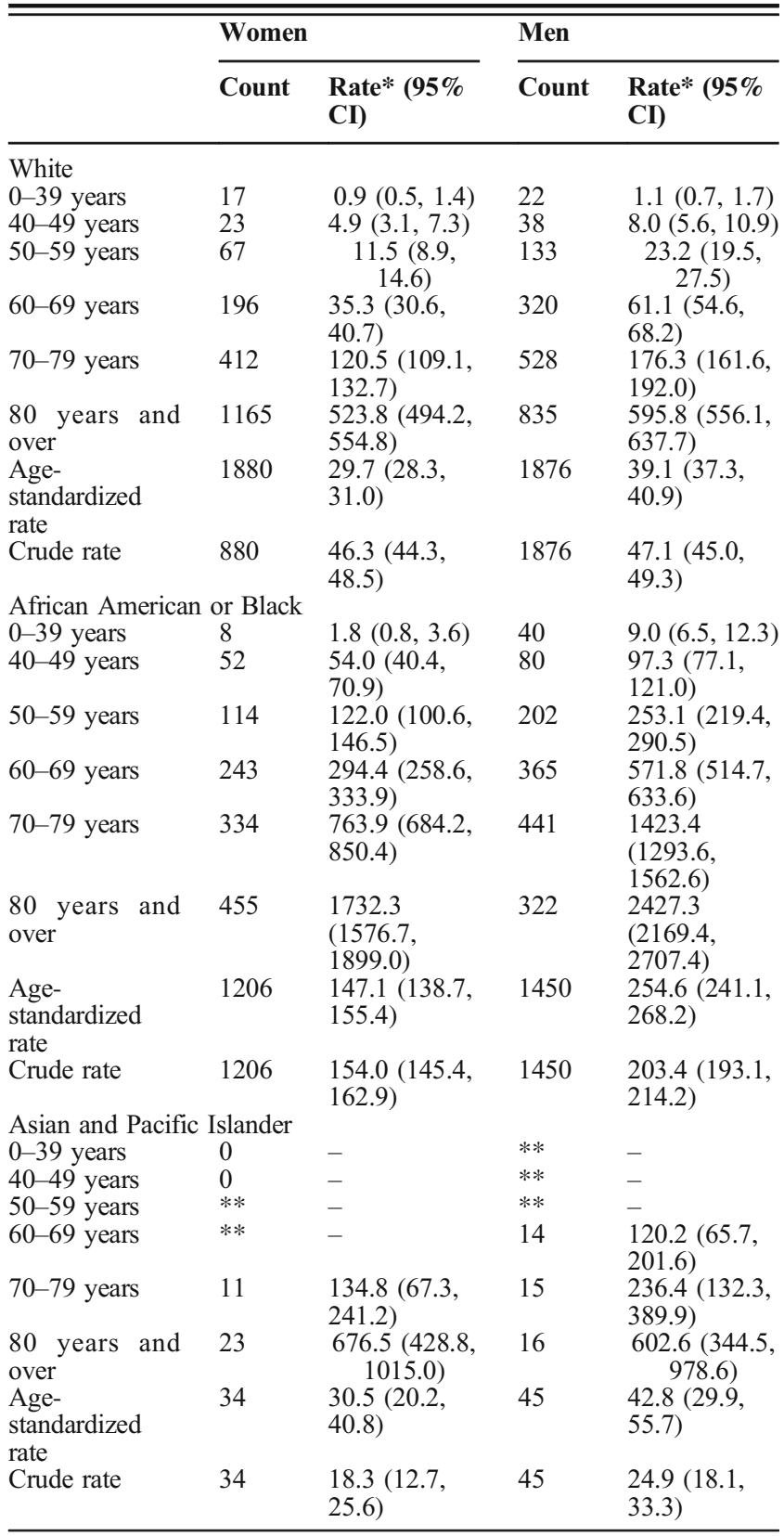

*Rate per 100,000

**Data suppressed due to a cell size between 1 and 5

-Rates for counts less than or equal to five may be statistically unstable and are not reported

Black women, 42.8 (29.9-55.7) for Asian/PI men, and 30.5 (20.2-40.8) for Asian/PI women (Fig. 1).

The age-standardized COVID-19 mortality rate ratio for men compared to women among Black individuals is 1.7 (95\% CI: $1.5-2.0)$ and only $1.32(1.2-1.5)$ among white individuals in MI. In GA, the corresponding ratio is 1.5 (1.3-1.7) among Black individuals and 1.4 (1.2-1.6) among white individuals. On the additive scale, the rate difference for men compared to women among Black individuals is 107.6 (81.2-133.7) and only 9.5 (5.8-13.2) among white individuals in MI. (Table 3). The Black compared to white rate ratio among men is 6.5 (5.8-7.3) and among women is 5.0 (4.4$5.6)$ in MI. The equivalent ratio in MI is 2.4 (2.1-2.7) among men and 2.2 (2.0-2.5) among women (Table 3).

In Michigan, the age standardized COVID-19 mortality rate among Black women was $5.0(4.4,5.6)$ times the rate among white women, while the rate among white men was only 1.3 $(1.2,1.4)$ times the rate among white women. Additionally, the rate among Black women was $4.8(2.7,8.4)$ times the rate among Asian/PI women while the rate among Asian/PI men was only $1.4(0.7,2.9)$ times the rate among Asian/PI women. The pattern in Georgia was the same, but the magnitude of the ratios was lower (Table 4).

\section{DISCUSSION}

Our results show that in GA and MI, Black men experience the highest COVID-19 mortality rates, higher than white men (128.5 compared to 53.2 deaths per 100,000 in GA, 254.6 compared to 39.1 in $\mathrm{MI}$ ), Black women (128.5 compared to 84.1 in GA, 254.6 compared to 147.1 in MI), and white women (128.5 compared to 38.2 in GA, 254.6 compared to 29.7 in MI). While the data show that men are at higher risk of COVID-19 death compared with women across racial/ethnic groups, and that Black men and women have markedly higher risk of COVID-19 death compared with White and Asian/PI men and women within gender groups, an intersectional analysis reveals more complex patterns. Thus, our results show that Black women have a higher mortality rate than both white and Asian/PI men as well as white and Asian/PI women. Additionally, the sex disparities in COVID-19 mortality rates vary dramatically between Black, white, and Asian/PI populations in GA and MI. In MI the COVID-19 mortality rate for Black men is $170 \%$ times the rate for Black women, which is significantly higher than the equivalent ratio among White individuals: the rate is only $130 \%$ higher for white men compared to white women. In GA, while not significantly different, the rate is $150 \%$ higher for Black men compared to Black women, and $140 \%$ higher for white men compared to white women. In both states, the gap between the rates for Black women compared to white women is higher than the gap between the rates for white men compared to white women. These patterns suggest that it is overly reductive to treat the sex disparity as a biological feature that is constant across racial groups. Rather, efforts to explain these disparities must focus on how differential risk of exposure and differential susceptibility to COVID-19 complications are jointly patterned by the gendered and racialized nature of work, housing and living conditions, comorbidities, and access to care.

The magnitude of COVID-19 mortality rates differs in MI and GA. The differences likely reflect a combination of factors, such as timing of the COVID-19 surge, demographics, COVID-19 policies, and other societal factors. Exploring the factors driving these differences is beyond the scope of this paper. 


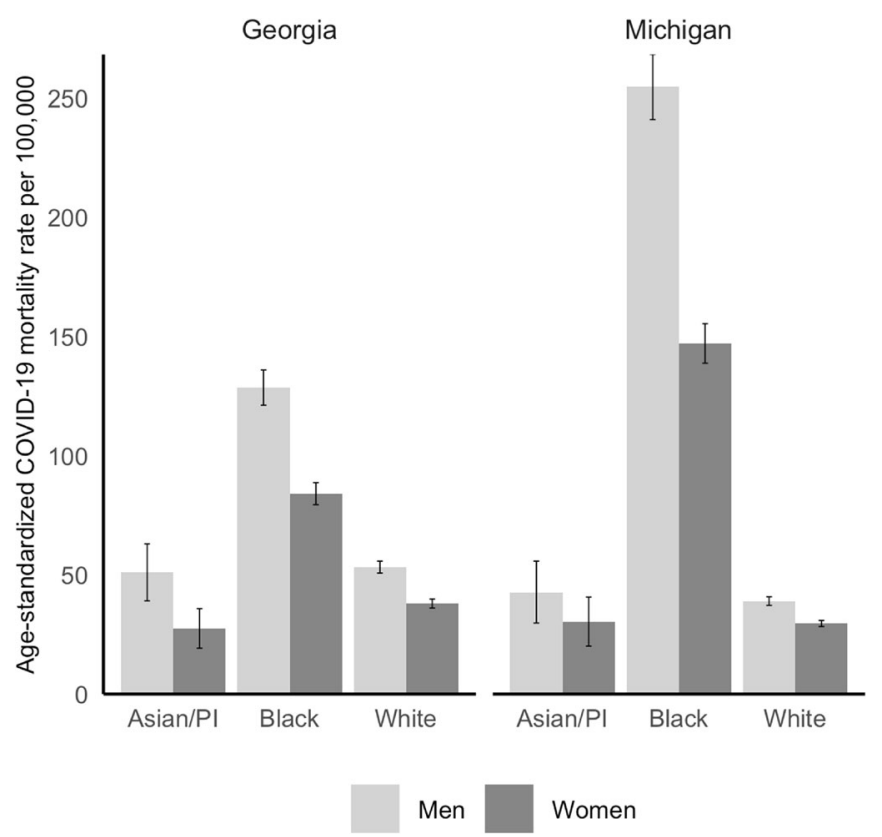

Figure 1 Age-Standardized COVID-19 Mortality Rate by Race and Sex in Georgia and Michigan USA. Asian/PI, Asian or Pacific Islander. Age-standardized rates were calculated using direct standardization and the 2000 US population as the standard.

Understanding these patterns, in particular the extremely high death rates of Black men and women, requires consideration of how social factors interact with gender and race to shape COVID-19 disparities. We conceptualize the category of race not as indicative of genetic differences, but instead as a marker of historical and ongoing oppression of communities and individuals based on racial category. ${ }^{15}$ Similarly, social context likely plays a critical role in observed sex-differences in COVID-19 mortality rates. ${ }^{16}$ The sex-disparity in COVID19 mortality rates varies widely both between US states and between countries, and over time. ${ }^{1,}{ }^{17}$ Our findings provide additional confirmation of social-contextual variation in COVID-19 sex disparities, as the mortality sex disparity differs dramatically across racial groups.

When considering how race/racism and gendered social contexts impact health, it is important to recognize that these societal factors can have different and complicated relationships to traditional understandings of social power within US society. For example, while men are usually considered the privileged group, it is well-documented that masculinity norms may nevertheless negatively impact men's health. ${ }^{18}$ In prior coronavirus epidemics, men were consistently less likely to report adhering to social distancing measures. ${ }^{19}$ In the current COVID-19 pandemic, men are less likely to report wearing masks than women and were 1.5 times less likely to be observed wearing a mask while shopping in a recent large, observational study. ${ }^{20}$ At least one study has found that selfreport of adherence to masculinity ideals is negatively correlated with mask-wearing for both men and women, though more so for men. ${ }^{21} \mathrm{We}$ did not find studies that simultaneously considered the effects of race and gender on social distancing or mask wearing, though we note that, in general, Black and Hispanic Americans are more likely to report mask wearing than white Americans. ${ }^{22}$
Likely far more explanatory of the race/sex results observed in this study than individual behaviors and beliefs are structural factors including occupation and access to healthcare. Overall, men comprise $57 \%$ of essential workers in the USA, but within categories of essential workers, women comprise over $60 \%$ of the workforce in healthcare support, healthcare practitioners, and personal care and social service essential jobs, while men comprise over $60 \%$ of cleaning and maintenance, production and transportation, protective services, and

Table 3 COVID-19 Age-Standardized Mortality Rate Ratios and Rate Differences in Michigan and Georgia, USA

\begin{tabular}{|c|c|c|c|c|}
\hline & \multicolumn{2}{|l|}{ Michigan } & \multicolumn{2}{|l|}{ Georgia } \\
\hline & $\begin{array}{l}\text { Rate } \\
\text { ratio } \\
\text { (CI) }\end{array}$ & $\begin{array}{l}\text { Rate } \\
\text { difference } \\
\text { (CI) }\end{array}$ & $\begin{array}{l}\text { Rate } \\
\text { ratio } \\
\text { (CI) }\end{array}$ & $\begin{array}{l}\text { Rate } \\
\text { difference } \\
\text { (CI) }\end{array}$ \\
\hline \multicolumn{5}{|l|}{ Black } \\
\hline Women & Ref & Ref & Ref & Ref \\
\hline Men & $\begin{array}{l}1.7(1.5, \\
2.0)\end{array}$ & $\begin{array}{l}107.6(81.2, \\
133.7)\end{array}$ & $\begin{array}{l}1.5(1.3 \\
1.7)\end{array}$ & $\begin{array}{l}44.3(29.9, \\
58.7)\end{array}$ \\
\hline \multicolumn{5}{|l|}{ White } \\
\hline Women & Ref & Ref & Ref & Ref \\
\hline Men & $\begin{array}{l}1.3(1.2, \\
1.5)\end{array}$ & $9.5(5.8,13.2)$ & $\begin{array}{l}1.4(1.3, \\
1.6)\end{array}$ & $\begin{array}{l}15.02(9.9, \\
20.1)\end{array}$ \\
\hline \multicolumn{5}{|c|}{ Asian and Pacific Islander } \\
\hline Women & Ref & Ref & Ref & Ref \\
\hline Men & $\begin{array}{l}1.4(0.7 \\
2.9)\end{array}$ & $\begin{array}{l}12.3(-14.9, \\
39.4)\end{array}$ & $\begin{array}{l}1.9(1.0 \\
3.5)\end{array}$ & $\begin{array}{l}23.5(-0.3, \\
47.2)\end{array}$ \\
\hline \multicolumn{5}{|l|}{ Men } \\
\hline White & Ref & Ref & Ref & Ref \\
\hline Black & $\begin{array}{l}6.5(5.8, \\
7.3)\end{array}$ & $\begin{array}{l}215.5(192.9, \\
238.0)\end{array}$ & $\begin{array}{l}2.4(2.1, \\
2.7)\end{array}$ & $\begin{array}{l}75.3(62.4, \\
88.2)\end{array}$ \\
\hline $\begin{array}{l}\text { Asian/ } \\
\text { PI }\end{array}$ & $\begin{array}{l}1.1(0.7, \\
1.8)\end{array}$ & $\begin{array}{l}3.6(-17.9, \\
25.0)\end{array}$ & $\begin{array}{l}1.0(0.7 \\
1.4)\end{array}$ & $\begin{array}{l}-2.0(-22.0 \\
17.8)\end{array}$ \\
\hline White & Ref & Ref & Ref & Ref \\
\hline Black & $\begin{array}{l}5.0(4.4, \\
5.6)\end{array}$ & $\begin{array}{l}117.4(103.4 \\
131.2)\end{array}$ & $\begin{array}{l}2.21(2.0, \\
2.5)\end{array}$ & $\begin{array}{l}46.0(37.9, \\
54.1)\end{array}$ \\
\hline $\begin{array}{l}\text { Asian/ } \\
\text { PI }\end{array}$ & $\begin{array}{l}0(0.6, \\
1.8)\end{array}$ & $\begin{array}{l}0.8(-16.3, \\
17.9)\end{array}$ & $\begin{array}{l}0.7(0.4, \\
1.2)\end{array}$ & $\begin{array}{l}-10.5(-24.5 \\
3.4)\end{array}$ \\
\hline
\end{tabular}


Table 4 COVID-19 Age-Standardized Mortality Rate Ratios and Rate Differences using a Common Race-Sex Reference Group in Michigan and Georgia, USA

\begin{tabular}{|c|c|c|c|c|c|c|c|c|}
\hline & \multicolumn{4}{|l|}{ Michigan } & \multicolumn{4}{|l|}{ Georgia } \\
\hline & \multicolumn{2}{|c|}{ Rate ratio $(\mathrm{CI})$} & \multicolumn{2}{|c|}{ Rate diff. (CI) } & \multicolumn{2}{|c|}{ Rate ratio (CI) } & \multicolumn{2}{|c|}{ Rate diff. (CI) } \\
\hline & White & Black & White & Black & White & Black & White & Black \\
\hline Women & Ref & $\begin{array}{l}5.0 \\
(4.4 \\
5.6)\end{array}$ & Ref & $\begin{array}{l}117.4 \\
(103.4 \\
131.3)\end{array}$ & Ref & $\begin{array}{l}2.2 \\
(2.0 \\
2.5)\end{array}$ & Ref & $\begin{array}{l}46 \\
(37.9 \\
54.1)\end{array}$ \\
\hline Men & $\begin{array}{l}1.3 \\
(1.2, \\
1.4) \\
\text { White }\end{array}$ & $\begin{array}{l}8.6 \\
(7.7, \\
9.7) \\
\text { Asian/PI }\end{array}$ & $\begin{array}{l}9.5 \\
(5.8, \\
13.2) \\
\text { White }\end{array}$ & $\begin{array}{l}225.0 \\
(202.5, \\
247.4) \\
\text { Asian/PI }\end{array}$ & $\begin{array}{l}1.4 \\
(1.3, \\
1.6) \\
\text { White }\end{array}$ & $\begin{array}{l}3.4 \\
(3.0, \\
3.8) \\
\text { Asian/PI }\end{array}$ & $\begin{array}{l}15 \\
(9.9, \\
20.1) \\
\text { White }\end{array}$ & $\begin{array}{l}90.3 \\
(77.7, \\
102.9) \\
\text { Asian/PI }\end{array}$ \\
\hline Women & Ref & $\begin{array}{l}1.0 \\
(0.6 \\
1.7)\end{array}$ & Ref & $\begin{array}{l}0.8 \\
(-16.3 \\
17.9)\end{array}$ & Ref & $\begin{array}{l}0.7 \\
(0.4 \\
1.2)\end{array}$ & Ref & $\begin{array}{l}-10.5 \\
(-24.5 \\
3.4)\end{array}$ \\
\hline Men & $\begin{array}{l}1.3 \\
(1.2, \\
1.4) \\
\text { Asian/PI }\end{array}$ & $\begin{array}{l}1.4 \\
(0.8, \\
2.3) \\
\text { Black }\end{array}$ & $\begin{array}{l}9.5 \\
(5.8, \\
13.2) \\
\text { Asian/PI }\end{array}$ & $\begin{array}{l}13.1 \\
(-8.3 \\
34.4) \\
\text { Black }\end{array}$ & $\begin{array}{l}1.4 \\
(1.3, \\
1.6) \\
\text { Asian/PI }\end{array}$ & $\begin{array}{l}1.3 \\
(0.9, \\
1.9) \\
\text { Black }\end{array}$ & $\begin{array}{l}15 \\
(9.9, \\
20.1) \\
\text { Asian/PI }\end{array}$ & $\begin{array}{l}13 \\
(-6.8, \\
32.7) \\
\text { Black }\end{array}$ \\
\hline Women & Ref & $\begin{array}{l}4.8 \\
(2.7 \\
8.4)\end{array}$ & Ref & $\begin{array}{l}116.6 \\
(94.7, \\
138.4)\end{array}$ & Ref & $\begin{array}{l}3.0 \\
(1.8, \\
4.9)\end{array}$ & Ref & $\begin{array}{l}56.5 \\
(40.9 \\
72.0)\end{array}$ \\
\hline Men & $\begin{array}{l}1.4 \\
(0.7 \\
2.9)\end{array}$ & $\begin{array}{l}8.4 \\
(4.8, \\
14.7)\end{array}$ & $\begin{array}{l}12.3 \\
(-14.9 \\
39.4)\end{array}$ & $\begin{array}{l}224.2 \\
(196, \\
252.1)\end{array}$ & $\begin{array}{l}1.9 \\
(1.0 \\
3.5)\end{array}$ & $\begin{array}{l}4.6 \\
(2.8, \\
7.6)\end{array}$ & $\begin{array}{l}23.5 \\
(-0.3 \\
47.2)\end{array}$ & $\begin{array}{l}100.8 \\
(82.5, \\
119.1)\end{array}$ \\
\hline
\end{tabular}

construction essential jobs. ${ }^{23}$ Preventative testing, use of personal protective equipment (i.e., masks and face shields), and other COVID-19 prevention measures may be enacted and enforced differently in healthcare settings compared to transportation or construction settings, influencing occupationrelated exposure risk. Racial segregation within already gender-segregated occupations - for instance the overrepresentation of Black women as nursing assistants and home health aides ${ }^{24}$ _ further shapes exposure risk. Furthermore, in the USA, Black workers are disproportionately represented in public-facing jobs with increased risk of virus exposure including in healthcare, transportation, and the service industry. ${ }^{25}$ Mass incarceration, disproportionately impacting Black men, worsens overall health and increases risk of contracting COVID-19 due to high-density detention facilities. ${ }^{26,27} \mathrm{Sim}$ ilarly, areas with greater racialized economic segregation and crowded housing have experienced higher COVID-19 mortality rates. ${ }^{2}$

Disparities in COVID-19 mortality replicate welldocumented racial and gender health inequities. In GA, for instance, Black men have the highest rates of cardiovascular disease, Black women and white men have relatively similar rates, and white women have the lowest rates. ${ }^{28}$ Such gender, race, and class health disparities in chronic diseases are widely understood as reflections of historical, structural, and contextual experiences of racism, discrimination, and inequity. ${ }^{29}$

This study has several limitations, largely due to limitations in the available data. First, at the time of download, GA and MI did not report ethnicity separately from race, making analysis of Latinx populations impossible. GA has recently begun reporting COVID-mortality by race and ethnicity, but MI still does not. Second, Michigan reported both "probable" and "confirmed" deaths while Georgia only reported "confirmed," making the data from MI and GA not fully commensurable. However, we note that only $3.3 \%$ of total Michigan deaths were "probable"; therefore, the influence of the differences in reporting practices between GA and MI is likely relatively small. Lastly, US State COVID-19 surveillance reporting nearly exclusively tracks only the binary of male/female for the variable of sex, obscuring the representation of transgender and non-binary individuals who do not identify as men or women.

While we use an intersectional framework to motivate statistical analysis of how sex/gender and race/ethnicity interact in relation to COVID-19 outcomes, examination of these data in relation to variables such as occupation, state-level policies, neighborhood characteristics, and socioeconomic status is required to situate outcomes in intersecting systems of power and oppression. Our findings demonstrate the urgent need for comprehensive federal and state reporting of socially relevant variables in relation to COVID-19 outcomes. ${ }^{30}$ Such data are fundamental to multi-dimensional analyses that can illuminate the patterns of inequity we uncovered within and across race and sex categories.

Acknowledgements: Joseph Bruch provided comments and feedback on manuscript framing and methods. Dr. Nancy Krieger provided initial conceptual and methodological feedback.

Corresponding Author: Tamara Rushovich, M.P.H.; Department of Social and Behavioral Sciences, Harvard T.H. Chan School of Public Health, Boston, MA, USA (e-mail: trushovich@g.harvard.edu).

Authors' Contribution Tamara Rushovich contributed to statistical analysis and interpretation, drafted manuscript, and contributed to edits. Marion Boulicault contributed to conceptualization, drafting, and editing of the manuscript. Jarvis Chen contributed to data analysis and interpretation. Ann Caroline Danielsen contributed to conceptualization and data collection. Amelia Tarrant contributed to 
the data collection and validation. Sarah Richardson contributed to framing the research project, data interpretation and conceptual elements, structure/logic/flow of manuscript, editing and writing. Heather Shattuck-Heidorn contributed to conceptualization, drafting, analysis, and editing.

Data Availability Data were derived from public domain resources. The data that support the findings of this study were downloaded from three sources:

1) Michigan.gov, at https://www.michigan.gov/coronavirus/0,9753,7-406-98163 98173\%2D\%2D-,00.html from the public use dataset "Cases by Demographics Statewide"

2) Georgia Department of Public Health at https://dph.georgia.gov/covid-19-daily-status-report from the link "Download the data (CSV)"

3) Centers for Disease Control and Prevention Bridged Race Estimates at https://wonder.cdc.gov/bridged-race-population.html from the 2018 vintage for the year 2018

\section{Declarations:}

Conflict of Interest: None of the authors have any conflicts of interest to declare.

\section{REFERENCES}

1. Harvard GenderSci Lab. US Gender/Sex COVID-19 Data Tracker. Published 2020. https://www.genderscilab.org/gender-and-sex-incovid 19. Accessed July 6, 2020.

2. Krieger N, Waterman PD, Chen JT. COVID-19 and overall mortality inequities in the surge in death rates by zip code characteristics: Massachusetts, January 1 to May 19, 2020. Am J Public Health. 2020;110(12): 1850-1852. https://doi.org/10.2105/AJPH.2020.305913.

3. Yancy CW. COVID-19 and African Americans. J Am Med Assoc. 2020;323(19):1891-1892. https://doi.org/10.1001/jama.2020.6548.

4. Krieger N. Epidemiology and the web of causation: Has anyone seen the spider? Soc Sci Med. 1994;39(7):887-903. https://doi.org/10.1016/ 0277-9536(94)90202-X.

5. Crenshaw KW. Demarginalising the intersection of race and sex: A black feminist critique of anti-discrimination doctrine, feminist theory, and anti-racist politics. Univ Chic Leg Forum. 1989;1(8):139-167. https:// doi.org/10.4324/9781315582924-10.

6. McCall L. The Complexity of Intersectionality. Signs J Women Cult Soc. 2005;30(3):1771-1800. https://doi.org/10.4324/9780203890882.

7. Georgia Department of Public Health. Georgia Department of Public Health Daily Status Report. Published 2020. https://dph.georgia.gov/ covid-19-daily-status-report. Accessed September 21, 2020.

8. Corona Virus, Michigan Data. Michigan.gov. Published 2020. https:// www.michigan.gov/coronavirus / 0,9753,7-406-98163 98173\%2D\%2D-,00.html. Accessed September 21, 2020.

9. Centers for Disease Control and Prevention. Bridged-Race Population Estimates. Published 2018. https://wonder.cdc.gov/bridged-race-population.html. Accessed July 6, 2020.

10. Klein RJ, Schoenborn CA. Age adjustment using the 2000 projected U.S. population. Natl Cent Heal Stat. 2001;(20):1-9.

11. Curtin LR, Klein RJ. Direct standardization (Age-Adjusted Death Rates). Heal People 2000 Stat Note. 1995;6:1-10.

12. National Center for Health Statistics. Technical Notes: Provisional Death Counts for Coronavirus Disease (COVID-19). Published 2021. https:// www.cdc.gov/nchs/nvss/vsrr/covid19/tech notes.htm. Accessed February 5, 2021

13. von Elm E, Altman DG, Egger M, Pocock SJ, Gøtzsche PC, Vandenbroucke JP. The Strengthening the Reporting of Observational Studies in Epidemiology (STROBE) statement: guidelines for reporting observational studies. Lancet. 2007;370:1453-1457. https://doi.org/10.1016/S01406736(07)61602-X
14. Krieger N, Chen JT, Waterman PD. COVID-19 Resources: Using the Methods of the Public Health Disparities Geocoding Project to Monitor COVID-19 Inequities and Guide Action for Health Justice. Published 2020. https://www.hsph.harvard.edu/thegeocodingproject/covid-19resources/. Accessed December 19, 2020.

15. Jones CP. Levels of racism: A theoretic framework and a gardener's tale. Am J Public Health. 2000;90(8):1212-1215. https://doi.org/10.2105/ AJPH.90.8.1212.

16. Galasso V, Pons V, Profeta P, Becher M, Brouard S, Foucault M. Gender Differences in COVID-19 Related Attitudes and Behavior: Evidence from a Panel Survey in Eight OECD Countries. Natl Bur Econ Res Work Pap Ser. 2020;27359. https://www.cambridge.org/core/product/identifier/CBO9781107415324A009/type/book_part\% http://www. nber.org/papers/w27359.pdf.

17. Global Health 5050. The COVID-19 Sex-Disaggregated Data Tracker https://globalhealth5050.org/the-sex-gender-and-covid-19-project/. Accessed December 19, 2020.

18. Courtenay WH. Constructions of masculinity and their influence on men's well-being: a theory of gender and health. Soc Sci Med. 2000;50:1385-1401. http://www.postpartummen.com/pdfs/SS\&M. PDF.

19. AlNajjar N, Attar L, Farahat F, AlThaqafi A. Psychobehavioural responses to the 2014 Middle East respiratory syndrome-novel corona virus (MERS CoV) among adults in two shopping malls in Jeddah, western Saudi Arabia. East Mediterr Heal J. 2016;22(11):817-823.

20. Haischer $\mathbf{M H}$, Beilfuss $\mathbf{R}$, Hart $\mathbf{M R}$, et al. Who is wearing a mask? Gender-, age-, and location-related differences during the COVID-19 pandemic. PLoS One. 2020;15(10 October):1-12. https://doi.org/10. 1371/journal.pone.0240785.

21. Palmer CL, Peterson RD. Toxic Mask-ulinity: The Linkbetween Masculine Toughness andAffective Reactions to MaskWearing in the COVID-19 Era. Polit Gend. 2020:1-8. https://doi.org/10.1017/ S1743923X20000422.

22. Kramer S. More Americans say they are regularly wearing masks in stores and other businesses. Pew Research Center. Published 2020. https://www.pewresearch.org/fact-tank/2020/08/27/more-americanssay-they-are-regularly-wearing-masks-in-stores-and-other-businesses/. Accessed December 19, 2020.

23. Barnes TD, Holman MR. Essential Work Is Gender Segregated: This Shapes the Gendered Representation of Essential Workers in Political Office. Soc Sci Q. 2020;101(5):1827-1833. https://doi.org/10.1111/ ssqu. 12850

24. Frye J. On the Frontlines at Work and at Home: The Disproportionate Economic Effects of the Coronavirus Pandemic on Women of Color. Cent Am Prog. Published online 2020.

25. Hawkins D. Differential occupational risk for COVID-19 and other infection exposure according to race and ethnicity. Am J Ind Med. 2020;(May):13-16. https://doi.org/10.1002/ajim.23145.

26. Saloner B, Parish K, Ward JA, DiLaura G, Dolovich S. COVID-19 Cases and Deaths in Federal and State Prisons. J Am Med Assoc. 2020;324(6):602-603. https://doi.org/10.1056/nejmp2014836.

27. Wildeman C, Wang EA. Mass incarceration, public health, and widening inequality in the USA. Lancet. 2017;389(10077):1464-1474. https://doi. org/10.1016/S0140-6736(17)30259-3.

28. Rana Bayakly A. Burden of cardiovascular disease in Georgia. Georgia Department of Public Health. Published 2015. https://dph.georgia.gov/ document/document/2012-cardiovascular-disease-program-and-datasummary/download. Accessed August 3, 2020.

29. Williams DR, Lawrence JA, Davis BA. Racism and Health: Evidence and Needed Research. Annu Rev Public Health. 2019;40:105-125. https:// doi.org/10.1146/annurev-publhealth-040218-043750.

30. Boulicault M, Danielsen AC, Bruch J, Tarrant A, Borsa A, Richardson S. Socially Relevant Variables In US State COVID-19 Surveillance Reporting: A Report Card. Heal Aff Blog. Published online 2020. https://www.healthaffairs.org/do/10.1377/hblog20200710.964611/ full/.

Publisher's Note Springer Nature remains neutral with regard to jurisdictional claims in published maps and institutional affiliations. 